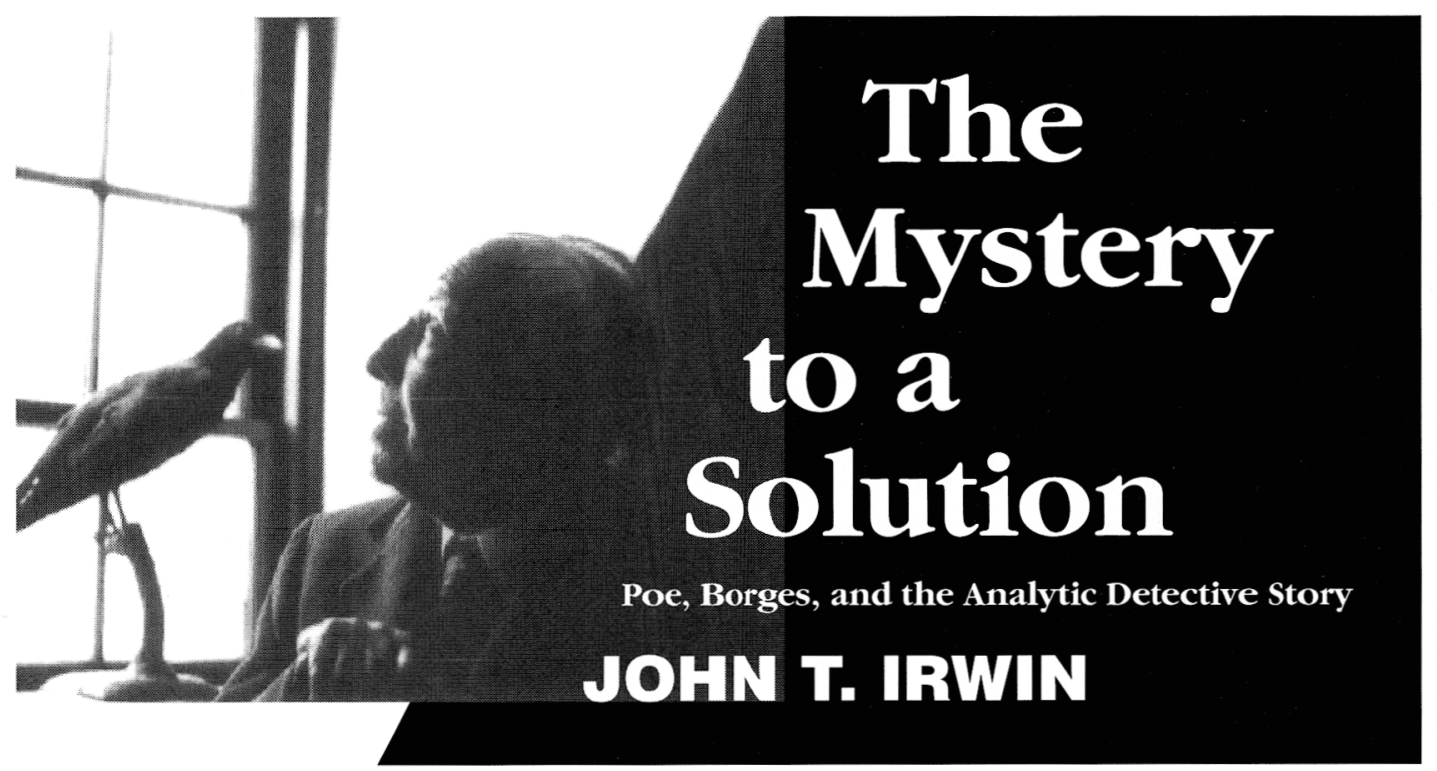

"As readers venture deeper, willingly or helplessly, into John Irwin's Mystery to a Solution, they begin to feel that this labyrinthine exploration of Poe and Borges is also bythose architects of mazes, spinners of paradoxes, and plotters of invisible symmetries. As in his previous studies of American literature, Professor Irwin traces unsuspected substructures with the eye of a magician and the skill of an anatomist."

\section{-Guy Davenport}

"John Irwin has written an amazing book-a great labyrinth of reflections (in the richest double sense of the word), of dizzying intertextuality and dazzling analyses, which constitutes a magnum opus of contemporary literary criticism. The labyrinth leads back and forward to earliest mythologies; it keeps returning to the fiction of Borges and Poe; its signposts are in many languages - Greek and Latin, French, Spanish, and German, as well as the languages of literary theory, scriptural hermeneutics, anthropology, psychology, music, philosophy, chess, mathematics, and the fine arts, all interwoven in an elegant, poetic English baroque; as we proceed, it gives us brilliant commentaries on the art of Borges and Poe, with detours illuminating the entire range of the Western tradition from Hesiod through Joyce, upon which that art was constructed; and by the end, when it 'circles back to the beginning,' we have discovered the astonishing mysteries of one of the oldest, most pervasive, and most complex genres, the 'analytic detective story.' It is an exhilarating journey for the reader and, for the author, a monumental achievement."

\section{-Sacvan Bercovitch}

"The Mystery to a Solution is the most perceptive and erudite book on Borges yet written, while being one of the most entertaining works of criticism that I have read in recent years. I was afraid that books like Irwin's were not being written any more."

-Roberto González Echevarría
"The Mystery to a Solution lives up to its title; it is a dazzling intellectual quest-romance that links Poe and Borges to an occult, hermetic, hermeneutic tradition featuring the problematics of quantity, figuration, space, time, and perception."

\section{-G. R. Thompson}

"A masterful blend of literary criticism, philosophy, game theory, classical learning, the history of science, and the occult. From the multidimensional problems of detection and mystery, Irwin creates his own critical labyrinth in which theory, storytelling, and history are held in precarious balance and in which the world of the modern is illuminated as though in a new text by Poe and Borges."

\section{-Eric J. Sundquist}

"A brilliantly original book. Like his authors, Irwin is a master of arcane knowledge, a careful, painstaking reader, and a brilliant theoretician of literature."

\section{-Edgar A. Dryden}

"The brilliant decoder of American Hieroglyphics applies his cryptoanalytical skills to another kind of literary puzzle, with results that would surely have delighted Poe and Borges."

\section{一John Barth}

"A stunning book, profoundly researched. Professor Irwin has written, in a most engaging style, an expansive and compelling study of Poe and Borges. Poe's Dupin stories, both paradigmatic of analytic detective fiction and serious literature, are the ground for Irwin's exploration of the essential embrace of lucid analysis and opaque mystery."

\section{-Martha Grimes}

$\$ 36.95$ hardcover 


\section{Who put}

\section{the}

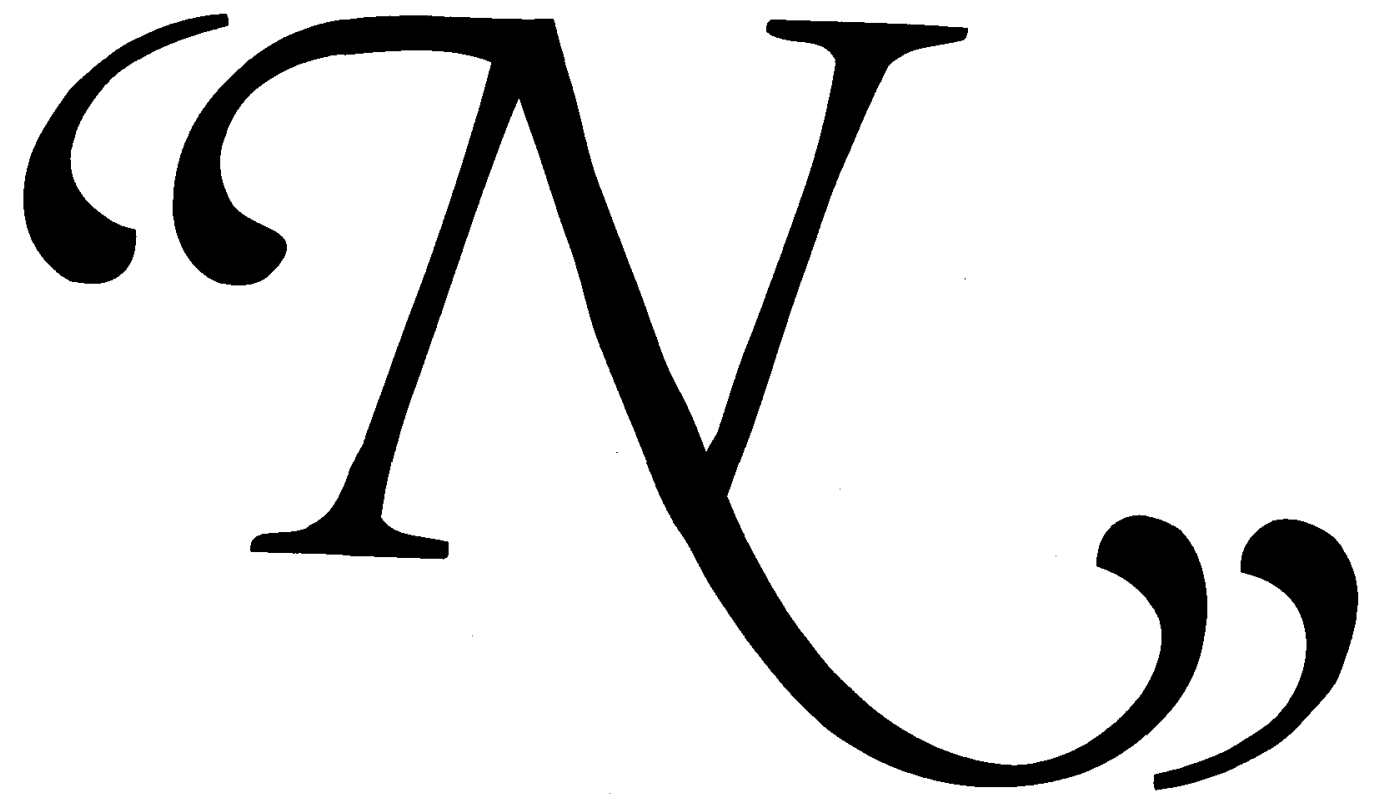

in

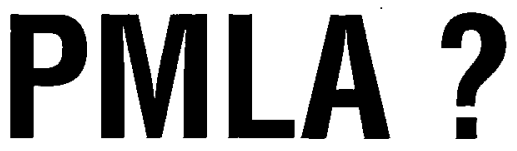

Booths 225 \& 226 • University of Nebraska Press Lincoln, NE • 800-755-1105 